\title{
From the desk of Editor-in-chief
}

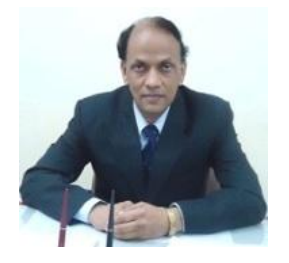

"May everybody witness the Global Peace."

It's a moment of glory and landmark in my career to announce the launching of the inaugural issue of Nepalese Journal of Radiology (NJR), a historical beginning in the history of Nepal Radiologists' Association (NRA). In the last decade the revolution in the development of Radiological science has stimulated newer Radiological publication both online and conventional versions as a result scientists, educators, practicing Radiologists' and Researcher's has an opportunity to make himself/herself update with emerging technology and skills for betterment of patient care. In Nepal such publication was lacking hence Nepal Radiologists' Association has initiated a historical beginning to launch Nepalese Journal of Radiology. NJR will be a great help to all those related to Radiological Sciences.

The editorial board has put a lot of effort in maintaining the quality standards of NJR. In inaugural issue consisted of research article from Nepal, other SAARC countries and from overseas. The launching of NJR in this context is extended to overcome some of the hurdle the Radiological Community is facing and will find a means to communicate and disseminate clinical and scientific achievements in the country, in the region and to the global community of Radiological Professionals.

It is important to realize that Radiology Journal should aim to provide recent and useful information to Radiologists for its application in practice. Certainly a quality published research work will allow achieving this goal. We believe that anonymous peer review of the articles before being accepted for the publication improves the quality of the Journal however the readers need to evaluate the scientific and methodological quality and reproducibility of the result. We believe that review articles by experts in the related field might be of more value than traditional text book. The editorial board of NJR hopes to receive such review article submission. 
NJR is aimed on receiving the articles focused on translating experience and research into clinical practice stimulating Radiologists of younger generation to conduct scientific research work and publishing their achievements.

The usefulness of the Journal/article will be judged on the basis of healthy, constructive comments and criticism which will be published in the subsequent issue of the Journal. I believe in regular and timely peered review publication and steady improvements of the Journal to achieve excellence (As said Rome is not built in a day) which will be only possible with continuous dedicated commitment and efforts of the experts of Radiological Sciences of the country. We welcome any suggestion and advice an experts from across the world.

The timely completion of this historical inaugural issue of the Nepalese Journal of Radiology has become possible only because of tired less effort of entire editorial board, constant guidance and encouragements of national and international advisors and by many other well wishers. I make special note of dedication and commitments with many sleepless nights shown by one of our editor Mr. Arun Gupta (Physicist). I feel honored and privileged to thanks all editorial team of NJR for their contribution and commitments.

Thanks

May God bless all of us. Long live Nepal Radiologists’ Association.

Prof. Dr. R.K. Rauniyar 